ARTICLE

https://doi.org/10.1057/s41599-019-0239-4

\title{
OPEN
}

\section{Tuberculosis in the borderlands: migrants, microbes and more-than-human borders}

\author{
Komatra Chuengsatiansup ${ }^{1} \&$ Wirun Limsawart ${ }^{1}$
}

\begin{abstract}
Multidrug-resistant tuberculosis (MDR-TB) has been a widely recognized threat since the TB epidemic was declared a global emergency in the 1990s. The epidemic is particularly critical in the borderlands where humans and microbes move across geographic borders. In this article, we explore the contingency of human-microbe relations in ThailandMyanmar borderlands. Initially constituted by the colonial encounters, the Siam-Burma border's continuing existence was constantly enacted, negotiated, and co-produced through the entangled interplay of various actors, microbes and pharmaceuticals included. We examine how global forms such as biomedical science, epidemiological practices, and public health interventions were actualized in an attempt to control MDR-TB in this borderland. While disease surveillance and control were seemingly hindered by the permeability of the border and geographic mobility of migrants, the potency of Mycobacterium tuberculosis to lie dormant in human bodies for long periods of time without symptoms posed an additional challenge to epidemiological attempts to segregate the healthy from the contaminated. Combining ethnographic materials from Umphang District, Tak Province at the western border of Thailand with national policy analysis, natural history, and microbiological insights, we reveal how the indeterminacy of borders and complex microbe-human entanglements necessitate changes in the prevailing biocontainment model of infectious disease control. We propose that disease surveillance and response need to transcend the rigid geographic notion of space and include a more flexible topological conception of spatiality that embraces the fluidity of pharmaceuticals, microbes, and human relations. This reinvention of the spatial approach in epidemic control begins by attending more closely to the entanglement of human-microbe relations in the more-than-human borders.
\end{abstract}

\footnotetext{
${ }^{1}$ Society and Health Institute, Health Technical Office, Office of the Permanent Secretary, Ministry of Public Health, Nonthaburi, Thailand. Correspondence and requests for materials should be addressed to K.C. (email: komatra@health.moph.go.th)
} 


\section{Introduction}

uberculous bacilli have a long history of co-existence with humans. Geographically, the bacterial ancestor, just like ours, first appeared in and later migrated out of Africa (Gutierrez et al., 2005). Analysis of Mycobacterium tuberculosis and human mitochondrial genomes reveals bacterial-host coevolution where the microbe successfully adapted and exploited the densely populated human communities during the Neolithic Demographic Transition. (Roberts and Buikstra, 2003, pp. 114-125). From antiquity to the present, the entanglement of this pathogenic agent in human societies has profoundly transformed human histories. Although anti-TB drugs have been available since the 1940s, tuberculosis has remained one of the biggest killers of our time. In the past two centuries, this airborne communicable disease has reportedly killed millions of people throughout the world (McMillen, 2015, p. 2). The history of public health to control this deadly disease has been considered a history of failures (Keshavjee and Farmer, 2012; McMillen, 2015). Disease prevalence and mortality are particularly grievous among the poor and socially marginalized; migrants, refugee, and displaced people living and working in deplorable conditions are among the most vulnerable populations.

Thailand has been actively participating in the global movement for TB control since the 1950s. ${ }^{1}$ Extensive coverage of vaccine together with the expansion of health services providing anti-TB treatment helped lessen Thailand's burden of TB during the 1970s and 1980s. The outbreak of HIV and the subsequent epidemics of multi-drug resistant tuberculosis (MDR-TB) in 1990s led the World Health Organization (WHO) to declare TB as a "global emergency" (World Health Organization, 1994). Countries with the highest rates of infection were identified as High-Burden Countries (HBCs). These countries, 22 in total, including Thailand and Myanmar, accounted for more than $80 \%$ of all estimated incident cases worldwide. In WHO's recent End TB Strategy (2016-2035) that sets "TB eradication" as the global target, both Thailand and Myanmar are still on the new list of 14 HBCs with the highest problems of TB, TB and HIV co-infection, and MDR-TB (World Health Organization, 2015a, 2015b). As a borderland between two HBCs, the Thai-Myanmar border is identified as a high-risk zone and it poses a formidable challenge to the national and global TB control effort.

In 2017, Thailand's National Strategic Plan on TB (2017-2021) was developed to contain the TB epidemic (Department of Disease Control, 2017). Various interventions were formulated including the strengthening of the DOT (Directly Observe Treatment) program, the use of cocktail drugs, active case finding for early detection of new cases and a new clinical guideline for the treatment of TB. With a high prevalence of TB cases, "migrants" were identified as a high-risk population demanding special attention. National plans and strategies were seemingly well formulated in accordance with the international guidelines. The actual implementation in the borderland, however, was much more complicated. As Myanmar's economy opened up to the outside world in the 1990s, after decades of isolation and a calamitous period of military dictatorship, border trade flourished. In addition to refugees fleeing the atrocity of armed conflicts in the past decades, migrant workers seeking employment opportunities rushed into Thailand. Transborder mobility involved more than human: migration, commodities, and spontaneous pathogenic exchange. The lack of accessible medical facilities in Myanmar also forced patients to travel across the border to seek medical care, including treatment of tuberculosis. As TB incidence in Myanmar is more than two times higher than Thailand, ${ }^{2}$ patients with tuberculosis seeking care in Thailand were viewed as potential risk of spreading disease (Voravit, 2008) and also alleged of being "non-compliant," discontinuing medication before completion, thus further complicating the national effort to control TB (Hemhongsa et al., 2008).

In this work, we examine the attempt to contain the TB epidemic and the dynamic entanglement of human-microbe relations at Thai-Myanmar borderland. At first glance, population mobility and the permeability of the border seemed to undermine the disease surveillance and control effort. A closer look at how the border was continuously enacted, negotiated, and coproduced through the entangled interplay of various actors, however, suggests a much more complicated condition. In attempting to reveal the indeterminacy of the borders and complex microbe-human entanglement, we will first examine how the state borderline was constituted by the colonial encounter. Its continuing existence, however, was far from being geographically defined. Rather, it was constantly produced and reproduced through the entangled interplay of various actors, microbes, and pharmaceuticals included. It was within this context that the attempt to control MDR-TB was actualized. While the effort to control TB relied heavily on the "outbreak narrative" (Wald, 2008) to identify sources of infection, or carriers, who spread disease across epidemic geography, we reveal how its actual operation in this borderland was complicated not only by the complex border topology, but also the mundane biotic and material encounters that create the conditions of pathogenic possibility. We argue that the prevailing biocontainment model of infectious disease control needs to refrain from the geometry of fixed distances and defined borders. Disease surveillance and response need to transcend the rigid geographic notion of space and include a more flexible topological conception of spatiality that embraces the fluidity of pharmaceuticals, microbes, and humans.

\section{Fieldwork}

Our primary ethnographic site was Umphang District. It is located in the southernmost corner of Tak Province on the ThaiMyanmar border. Surrounded by wildlife sanctuaries and the Tenasserim Range, the small town supports a population of 60,000 , the majority of whom are ethnic Karen. Route 1090 is the only highway connecting the remote district to Maesot, a gateway town between Thailand and Myanmar. This acclaimed $164 \mathrm{~km}$ long road containing 1219 hairpin bends and switchbacks through mountainous landscape was constructed in the 1970s as part of the fight against communist insurgency (Fig. 1).

In the opposite direction, an old road exists which connects Umphang town to the Karen state in Myanmar. This lesserknown road has been used by local people for centuries prior to the existence of the Thai-Myanmar border. The border village of Perngklerng has served as the gateway for merchants who come to trade and migrants seeking jobs or health care at the local health facilities. Although the Perngklerng health center was primarily constructed to provide health services for local residents, people across the border have regularly come to seek care from this state-owned facility. Nearly halfway between Perngklerng and Umphang town, the $\mathrm{Nu}$ Po refugee camp is accessibly located at approximately ten kilometers from the border. It was set up in 1997 to accommodate Karen refugees fleeing the atrocities in the armed conflict between the Burmese and the Karen National Union (KNU) forces. Health care services are also provided at $\mathrm{Nu}$ Po refugee camp. A field hospital run by international humanitarian organizations in the refugee camp offers medical services not only for refugees but also for local villagers and patients from Myanmar. Patients with less serious health problems may also acquire medical remedies from several drug stores carrying a wide variety of pharmaceuticals in the camp. 


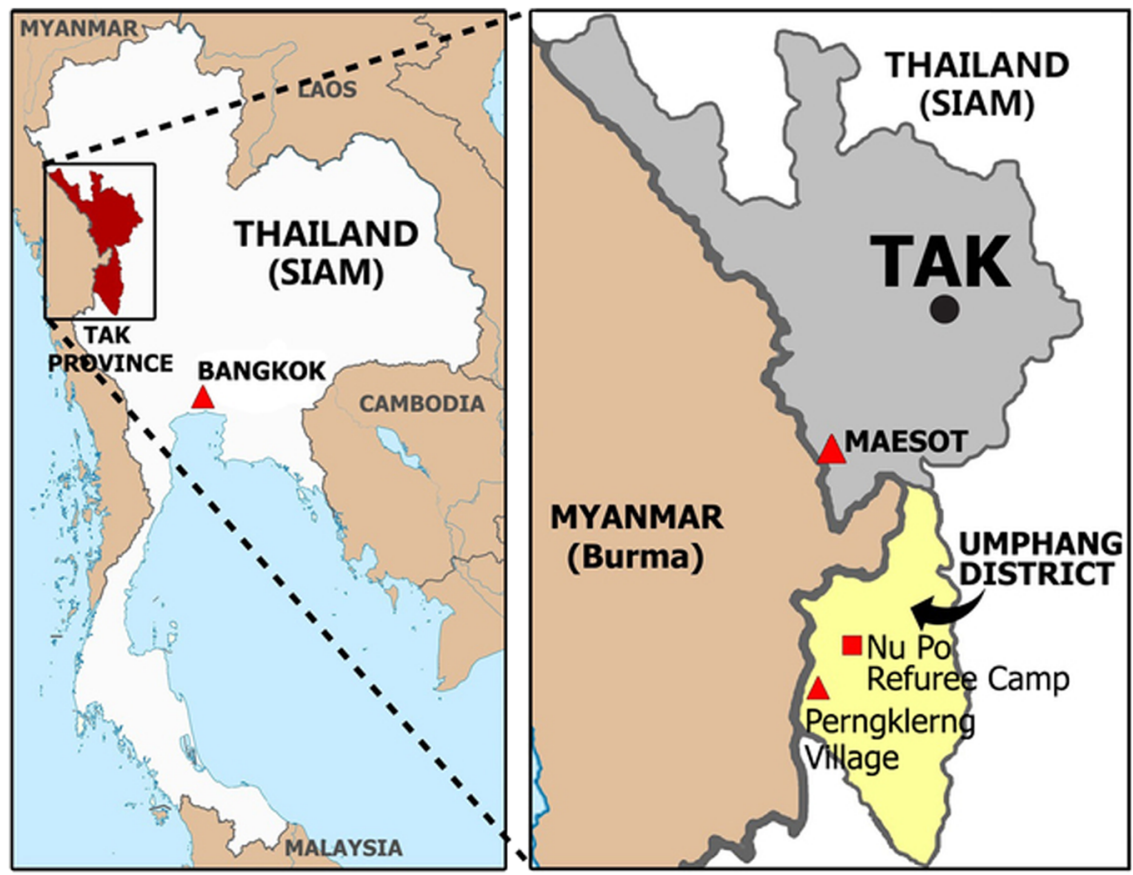

Fig. 1 Map of Tak province and umphang district on the Thai-Myanmar border

More serious medical conditions require approximately $2 \mathrm{~h}$ of additional travel to Umphang hospital.

While the majority of Karen people reside in Karen State in Myanmar, more than a million ethnic Karen live in Thailand. In addition to natives who have been living in Thailand for generations, the war between KNU and Burmese military, one of longest wars in Burmese history, has forced a great number of Karen people to flee and find refuge in Thailand. The role of the Thai state in employing the Karen as a buffer zone, although vehemently denied by the Thai government, contributed significantly to the Karen predicament (Fong, 2008, p. 269-271). In its perceptible humanitarian roles, Thailand has opened doors to refugees and set up nine refugee camps along the western border. One of them is Nu Po camp in which 14,000 refugees reside. Despite their refugee status, traveling outside the camp is not forbidden. Some of them are employed to work locally in Umphang.

Local people in this area have a long history of traveling across boundaries. Our fieldwork too has taken us across places and borders. Nonetheless, we have worked extensively with the local health team at Umphang Hospital and have spent considerable time in a Karen community to explore the contingent borders and the entanglement of human-microbe relations in this borderland.

\section{Borders and the colonial order}

Borders are multiple. Not only imbued with different meanings, borders are also "enacted" and "practiced" with different logic (Green, 2012; Mol, 2002). They are not merely objects being constructed and acted upon, for they constantly and actively shape human activities and histories. Just as realities are multiple and are performed in many different manners (Mol, 2002, p. 182), the multiplicity of borders arises and continually co-exists as articulations of the practices that produce them. Prior to the British colonization, Burma did not exist as a single territorial entity within a geographically defined border. The region was characterized by several kingdoms replete with ever-shifting alliances and constant wars ${ }^{3}$. The central plain was ruled by the Burmans, surrounded to the west by the Arakan, while the mountainous highlands were home to the Shan, Chin, and
Kachin, and the lower land was occupied by the Mon. The Karen people have emerged as an established ethnic population in late 16A.D., occupying the west of the Tenasserim Range. Borders between these nations were fluid. The arrival of the British ushered in drastic changes in not only power dynamics between various ethnic groups but also the geopolitics of the region.

After three Anglo-Burmese Wars over a period of 60 years, the British finally conquered the entire Burma Empire in the 1880s. The presence of the colonial British with its divide-and-rule policy exacerbated the prevailing conflicts between the Burman and other ethnic groups. Some ethnic groups welcomed the changes brought about by the British, perceiving colonial intervention as liberating them from the Burman domination. Karen people, in particular, became a close British ally. They had helped the British fight the Burmese. A significant number of Karen also converted to Christianity. This further complicated the intergroup relations since the majority of Burman were Buddhists, and they felt resentful as ethnic communities not only joined the foreign occupier but also converted to the foreign faith. As the Anglo-Burmese wars erupted, the Karen did not hesitate to take sides with the British. They expected that, with all the support they provided for the British, an independent Karen state would become a reality.

As British colonial power declined due to the impact of World War II (1939-1945), the historic Panglong Conference was held in 1947 to discuss the future of Burma. Motivated by the prospect of independence from Britain and the future of a unified republic, many ethnic groups agreed to join and build the Union of Burma. Nevertheless, Karen leaders were confident that they had strong claims for self-rule and did not commit to joining the Union. The agreement was led by Burmese general and national hero Aung San who negotiated and succeeded in concluding the agreement. But soon after, Aung San was assassinated, and none of those agreements was ever honored. The new Burmese government refused any autonomy to non-Burman ethnic regions. The British in the wake of the WW II had too many problems to struggle with and, in the end, took no necessary action to safeguard the autonomy of Burma's ethnic nationalities. Feeling betrayed by the British and further infuriated by the unjust new Constitution, 
many ethnic groups started to rebel against Burmese rule. When they were heavy-handedly suppressed by the military junta, they began their armed struggle in response. The Karen, in particular, have been forcefully engaging in the military insurgency, one of the longest and on-going civil wars in modern human history.

The British's conquest of Burma has completely upended the long history of conflicts and warfare between Siam and Burma. Although the colonial presence was a threat to its sovereignty, Siam was able to remain independent by situating itself as a buffer state between the British and the French. In the aftermath of WW II, while Burma was engaging with the ethnic insurgency, Thailand, with its own problems of communist insurgency during the Cold War, was keen to utilize ethnic minorities at the border as a buffer zone to safeguard its sovereignty (Fong, 2008, p. 270). Karen insurgent organizations were also adept in spatio-political warfare. They employed the guerilla tactics of hit-and-run and fled into the mountainous borderland where the Burmese military, due to concern over unnecessary conflict with Thailand, refrained from pursuing them. Non-violent Karen activists also occasionally organized their campaigns across the border in Thailand to raise international awareness and support (Henry, 2011, p. 90).

This brief account provides an essential background of the plight of the Karen who live at the Thai-Myanmar borderland. It demonstrates how the Thai-Myanmar border was constructed. As the account suggests, the border between Myanmar and Thailand was constituted less as a "borderline" between well-defined geographic entities than a spatial arrangement, or a "borderland," in which domination, contestation, and power negotiation took place (Hinchliffe et al., 2013). Although the era of colonial conquest and occupation as such has ended, the post-colonial bordering practices carry over the spatio-political legacy that forces an arbitrary fault-line and splits the Karen people at the border of two nations.

\section{Bordering practices and transborder mobility}

Borders are conceived via certain spatial conceptions. Different conceptions, in turn, affect our perception of proximities, distance and how we differentiate spatial aspects of reality. Yet borders do not just conceptually exist, they invite and require actions to be made real. As Sarah Green puts it, "borders are the outcomes of ongoing activities" (Green, 2012, p. 576). In other words, borders always require enactments or certain forms of bordering practices. Bordering practices, in turn, gain their legitimacy and authority by committing themselves to a higher order of logic. Before the arrival of the British, the region was a conglomerate of several kingdoms each exercising their relative autonomy over an ill-defined territory. Territoriality was fluid. It was conceived and enacted by a logic of the dominant and vassal states which institutionalized its mode of "bordering practice" by which people could and did move rather freely with little if any administrative barriers. In wars, people from the defeated nation were taken as captives and relocated to increase the conqueror's pool of manpower. In this "logic of centers and peripheries" (Green, 2012 , p. 577), such a bordering practice did not require certain people to be attached exclusively to certain territories. This was in stark contrast to the European logic of territorial sovereignty, where claims of land ownership involved a new form of bordering practice that required the geographical intensification of power. The need to secure nation-state boundary made territorial demarcation essential.

British colonial encounters constituted the western border of Siam. At the end of the Third Anglo-Burmese War, on 1 January 1886, Burma was colonized entirely by the British Empire. During the time of British rule, borders were enforced not only through treaties but also by informing local peoples as to which sovereign state they belonged. But the reinforcement was inconsistent at best. The geography of power did not put people in place. Rather workforces were mobilized in large numbers, through its porous territorial boundaries, to work for the British in exploiting rich natural resources such as jade, rubies, tin, tungsten, and, particularly, teak (Steinberg, 2001). The claim of territorial sovereignty with its bordering practices of border negotiations and policing, the imposition of demarcation lines in treaties, terrain surveys, and cartographic technique, seemed to imply borders as an instrument of spatial segregation. In its actual application, however, there were always activities, including material mobility, that constantly crisscross and contest territorial boundaries.

Borders were not always meant to mark the edge of existing territory. They appeared to be actively involved in the contingent world-making process. In the colonial practices of border negotiation, maps, as an "immutable mobile" (Latour, 1986), were indispensable. Cartographic representations and demarcation gave territories and boundaries the clout of verisimilitude. Yet, borders were and have always been blurry in the worlds of local people. Borders on the map were not correspondingly perceived on the ground. Although its presence and absence was conceived and practiced differently between colonial power and its subjects, it was, as Green puts it "both the separation and the relations between... [the] colonial logic about borders and the local people's rather different logic that....resulted in the particular 'borderness' of this place" (Green, 2012, p. 581).

Contrary to general understanding, the settlement of boundary disputes between British Burma and Siam did not result in a clearly defined border. The territorial agreement was drawn with vaguely demarcated borderlines, consisting for instance, in rivers, patches of forest, areas of plain or geographic board contour (Thongchai, 1994). On the table, borderlines drawn on a map may have been adequate for the diplomatic arm-twisting in colonial border negotiation. On the ground, however, borders were and have been much contested (Dulyapak, 2012; Kwanchewan, 2008). Even today, along more than 2000 kilometers of Thai Myanmar border, only 59 kilometers have officially been demarcated (Dulyapak, 2012, p. 377). As elusive as the border may be, a nation-state's assertion of territorial sovereignty has created a world in which Karen people were divided along the border of the place. While the logic of nationality prevails in official bordering practices, for local people, their geography is determined by different reasoning: the logic of sociality that makes transborder mobility a part of their everyday life.

\section{Migration, microbes and more-than-human borders}

"They are all the same. They look the same. Physically, you cannot tell a Thai from a non-Thai." Dr. Worawit Tantiwatanasap, the director of Umphang Hospital who has worked in Umphang for more than two decades, once told us. In the district of Umphang, more than $60 \%$ of local population are ethnic Karen. Citizen status of the Karen in Umphang is diverse, ranging from Thai citizen to legal immigrant, refugee, "stateless person" or illegal alien, all of whom are physically indistinguishable. With their indistinct physical appearance and the permeability of the border, Karen people can traverse or live in Thailand for decades with ambiguous legal status. Although Karen peoples consist of several different subgroups, each with its own language and tradition, Thai people, in general, call them either kariang (karen people), khon tangdao (foreigner or alien) or lump them together with Burmese as khon phama (Burma people). Although legal status of Karen residing in this borderland can be classified into 
several subcategories, they are often simply grouped as "Thai" and "non-Thai," where "Thai" being those grow up and live in Thailand, and "non-Thai" are Karen migrants from Myanmar. "Historically, they were the same people," Dr. Worawit added. "They were separated because of the national boundary imposed upon them by the state. They didn't draw it themselves."

Karen people had nothing to do with drawing the borderlines between Thailand and Myanmar, yet their lives in this borderland were deeply entwined with it. Relatives and kin were separated. While many of their relatives lived dangerous lives in war-torn zones across the boundary, some 100,000 fled and were put in the refugee camps along the Thai-Myanmar border. In certain aspects, the border forces into people's lives a structural classification of who they are. This borderness does not idly affix to specific geographic coordination, rather it stalks and taunts Karen people everywhere they travel. They can be stopped by "officers" in the middle of nowhere and asked to prove if they are Thai, either by showing their identification cards or, as in a well-known satirized story, by showing how good they are at singing the Thai national anthem. As Karen, their identities belonged to the enigmatic border where diseases and epidemics were most prevalent. They were suspicious of carrying germs and condemned as spreading diseases. Diseases and epidemics are at the border. Yet they are also actively participating in the co-production and reproduction of the border. It is as if "the border can be embedded in pathogenic life itself, rather than at the edge of territories" (Hinchliffe et al., 2013, p. 8).

Ethnicity transcends and preexists national boundary. Diseases, too, do not respect the logic of territorial sovereignty. Diseases such as malaria and tuberculosis are known to be epidemic across the western border. Although malaria in Thailand was successfully controlled in most parts of the country by 1970s, border areas ridden with ethnic conflict, armed violence, and guerrilla warfare are still fertile breeding grounds for malaria. In the 2000s, with the support from The Global Fund to Fight Tuberculosis, AIDS, and Malaria, the Tak Malaria Initiative Project was able to build several malaria posts along the Thai-Myanmar border. The project's vigorous campaign on early diagnosis and prompt treatment with mefloquine and artesunate successfully reduced the spread of malaria in the western border (Carrara et al., 2006). But for tuberculosis, as the discussion below will reveal, the pathogen-host relationalities and intensities which brought about its pathogenic potentials were considerably different. For one, malaria is vector-borne, able to be transmitted only in geographic areas in which mosquitoes of the genus Anopheles exist, and it needs only a short course treatment (days or weeks), while TB is airborne, spreading through human-to-human transmission and requires a long course of therapy ranging from six months (for ordinary $\mathrm{TB}$ ) to more than a year ${ }^{4}$ (for drug-resistant TB).

The TB epidemic in this borderland seemingly resolves around mobility of migrants and microbes. But the borderland between Myanmar and Thailand has become a high-risk zone not simply because migrants were spreading disease as they roamed. Transborder tuberculosis emerged within the unfolding of the colonial past, border politics, economic opportunities and microbial natural history that culminated in what Brown and Kelly call an "assemblage of disease", a space of mundane biotic and material encounters that create the conditions of pathogenic possibility (Brown and Kelly, 2014, p. 281, 282). Borderlands in which the dynamic entanglement of human-microbe relations took place are better conceived in terms of relationality, recognizing that the borders are always enacted, negotiated, and coproduced. Borders are multiple and the ways borders are made real involve the multiplicity and indeterminacy of material, microbe and human relations in which boundary makings are always entwined in more-than-human contexts.

\section{Biocontainment and the enacted borders}

In the 1960s, Thailand began its comprehensive National Tuberculosis Programme (NTP) in compliance to the recommendation of WHO's experts (Nadda, 2003). At its early stage, the need for long-term treatment with multiple drugs had made the program a non-cost-effective intervention. By the late 1980s, an effective Short-Course Chemotherapy (SCC), that shortened the treatment from years to only six months, was developed. Meanwhile, concern over the impact of medical expenditures on the global economy was rising. The World Bank, in its World Development Report 1993: Investing in Health directly addressed this issue. In this report, a new health metric was publicizedDisability Adjust Life Years (DALYs) - the aggregated number of healthy years a population lost by death or disability caused by a particular illness. It can be seen as a measure that places human economic value-years of productive lives-at the center of the public health discussion. As TB affects mostly people in the productive age, this new calculation made explicit the significant economic burden of TB and turned SCC into a highly costeffective health intervention. Thus, the World Bank correspondingly urged for investment in TB control (Becker et al., 2013). In April 1993, WHO declared TB a "global emergency" and called for collective action against the global TB epidemic using a costeffective, standardized regimen of DOTS (Directly Observed Treatment, Short Course) (World Health Organization, 1994). It was within this context of global assemblage that the attempt to control the MDR-TB epidemic at the Thai-Myanmar border was actualized.

Both Myanmar and Thailand are TB-laden countries. While epidemics in Myanmar have been complicated with a long period of armed conflict and civil war, TB control in Thailand was relatively more successful. Since the latter part of the twentieth century, case reports continuously declined in Thailand. In the 1990s, however, tuberculosis began rising, coinciding with the HIV epidemics (Yanai et al., 1996). According to the estimation by WHO in 2015, each year Thailand will have 120,000 new TB cases, 12,000 people will die from TB, and there will be 2200 new cases of MDR-TB. (Department of Disease Control, 2017, p. iii). The situation among vulnerable groups, especially migrants, is of particular concern. Recent estimations found that there were 4.5 million migrant workers in Thailand, of whom only 1.2 million are legally registered. There were also 150,000 refugees living in various border camps (Department of Disease Control, 2017, p. 11). As a large number of migrants and refugees reside along the western border of ThaiMyanmar, national and provincial agencies have been meticulously implementing WHO's recommendations.

In 2014, a team of health professionals from the Tak Provincial Health Office published a study of an MDR-TB epidemic in Tak Province (Yongyuth et al., 2014) reporting that most of the MDRTB cases in the province were amongst "non-Thai" people who resided in the five border districts. The statistical analysis indicated a higher prevalence of MDR-TB in "non-Thai" patients compared to "Thai" patients. At the national level, "non-Thai" TB patients were identified as more likely to fail to comply with the treatment regimen (Department of Disease Control, 2016). Noncompliance was seen to be the cause of the mutation of TB to drug-resistant strains. With this relatively simple metric, "nonThai" populations became the primary target for the prevention and control of MDR-TB epidemic in Tak Province. It is worth noting that the Thai/non-Thai distinction in this public health discourse was primarily based on ethnicity rather than nationality. The conflation of ethnic/nationality disregarded the complexity of citizenship and nationality of people in the borderland. Similar to the modernist states deploying formulaic schemes and metrics to simplify reality for their own administrative functionality, the way of state's seeing, as Scott (1998) points out, 
epidemiological operations resorted to conflating ethnic/nationality in rendering epidemics malleable.

The finding that the prevalence of MDR-TB among "nonThais" exceedingly outnumbered their Thai counterparts led the leader of the provincial TB team, a senior physician-epidemiologist, to conclude that "We have failed to control TB in 'our home' (banrao) because 'Burmese people' (khon phama) keep pouring in new germs. ${ }^{\prime 5}$ The team gave themselves a new mission, embarking on an ambitious project to control TB in "nonThai" populations across the Thai-Myanmar border within five to ten years. Equipped with a mobile digital chest X-ray (CXR) unit and the new genomic technology that could rapidly detect MDR$\mathrm{TB}$, known by health personnel as "Gene X-pert," up ten field stations, geographically distributed across the mountainous terrain of Umphang. Within a one-month long operation, 7000 individuals were rounded up for screening. Digital files of CXR were sent to radiologists at Maesot Hospital who identified 419 people as having abnormal CXR. The next step was to get the sputum of all those with abnormal CXR to do microscopic laboratory tests to determine if they were active $\mathrm{TB}$ cases, and, more importantly, whether any of them were suspected of carrying MDR-TB. Once identified as having TB, they could start the medication under DOTS, a medication under direct observation of health personnel five days a week over the period of six months, or 24 months in the case of MDR-TB. It was truly a geographically challenging endeavor since two-thirds of the 419 cases with abnormal CXR were "non-Thai" with half of them residing in Umphang, while the domiciles of the other half were somewhere in Myanmar territory.

This transborder screening project can be understood as a bordering practice of the Thai state aiming to "enact" (Mol, 2002) the boundary to ascertain the biosecurity of its citizens. Such an enactment, nevertheless, was based on the "myth" of an "outbreak narrative" by which the complex phenomenon of disease epidemics is reduced to a simplified plot of having a "carrier" as an "index case" who spreads the infection from a particular origin (Wald, 2008). This outbreak narrative had seemed to serve well since the early development of the field of epidemiology in the 1850s when John Snow traced a cholera outbreak back to a water pump in London (Johnson, 2006). As we shall see in the following section, the case of $\mathrm{TB}$, especially MDR-TB, is far more complex than the simple spatial notion of disease being spread from an identifiable origin and the existing biocontainment model of disease control implies.

\section{Life in the "Borderland"}

It was a sunny afternoon in 2016 when we first met Mo-e-se, ${ }^{7}$ a patient with MDR-TB. We met him at a small, one-story house in which he had been living alone for more than a year. A rather unobtrusive person, Mo-e-se looked content and very healthy. Even though he had been gaining quite a bit of weight since being given anti-TB medication, he still looked thin. After a brief exchange of courtesies, we sat down for an interview. The man in his mid-thirties sat back to recall his childhood memories. He was born and grew up in a small village in the Karen State of Myanmar. His mother was a rice farmer, and his father, liked most men in the village, worked as a Karen Soldier. When he was around 13 years old, his mother passed away unexpectedly due to some unknown fever. Then a few months later, his father was killed in a battle with the Burmese army. Afraid of being taunted and threatened by Burmese soldiers, he and his siblings fled into Thailand. He spent almost ten years living and working without any documents, earning his living by working day-labor jobs in Umphang District.
Although Mo-e-se stayed in a small humble house in Umphang, his connections extended far and beyond his geographic locale. His mobile phone helped him connect and access the vast network of Karen immigrants across Thailand. He soon met a Karen woman who he later married. At that time, she was working in Bangkok. Her uncle who had been working in the southern province of Songkhla suggested the couple join him for a better-paid job working in a shrimp farm. Songkhla was a faraway place, and Mo-e-se had no idea of its whereabouts. Neither the long distance nor his lack of geographic orientation hindered him, however, his wife's uncle had been working there for quite some time, and he trusted him. One thousand and five hundred kilometers away from the place he now called home was indeed a long distance, but Mo-e-se decided to go with little hesitation. It was as if the geographic distance was suddenly wiped out by the sociality of his kinship and shared ethnicity, like a folded handkerchief, in which widely separated places were drawn into "proxemic interaction" (Serres and Latour, 1995, pp. 60-61).

Working conditions in the shrimp farm were tough. The shrimp farm was located on the sea coast with gusty winds blowing all day and night. The cold wind in the chilly night urged him to smoke. The warmth from cigarette smoke he inhaled helped to keep his chest warm. After four years of exhausting work plus heavy smoking, he developed a chronic cough. He felt increasingly fatigued and soon found some blood stains in his sputum when he coughed. His wife insisted he seek care from the Ranod District Hospital. Without any health insurance, he bore all the costs of medicine and transportation himself. Although his sputum smear microscopic result came out negative, the CXR revealed pulmonary lesions, and the doctor at the hospital told him that he had TB. This diagnosis may not have been much of a surprise for him, as migrants view heavy smoking as a possible cause of TB. After six months of oral medication and regular visits to the hospital, he stopped coughing. Repeated X-rays confirmed his recovery and the doctor told him he had completed his treatment and was now a healthy man again.

Soon after, Mo-e-se and his wife moved to Bangkok to work in a garment factory. They then moved again to work in a sea-saltproducing plant in Samut Sakorn-a province with a high concentration of factories and thousands of migrant workers. This small coastal province in central Thailand was reported to have new TB case notification rates among migrants at a private hospital seven times higher than the overall rate for Asia (Ranee et al., 2015). After a few months, Mo-e-se began to develop a bloody cough. As his health condition worsened, his relatives in Umphang suggested he leave the city and come to rest with them. $\mathrm{He}$ decided to go back to Umphang, finishing his thousandkilometer journey across the country. Then he went to seek healthcare at Umphang Hospital and got a diagnosis that he once again had active pulmonary tuberculosis. Mo-e-se was immediately treated with anti-TB medication. At the same time, a specimen from his sputum was also collected and sent to the regional laboratory for further testing, including for the detection of drugresistant strains of TB.

We also learned other parts of Mo-e-se's story from his medical records and the report written by the district's Surveillance and Rapid Response Team (SRRT) - an official task force responsible for epidemic containment in the area. Although TB is not normally in the scope of SRRT's "rapid response," Mo-e-se case was a special as the report from the regional microbiological laboratory alarmingly confirmed that the germ he carried was not "normal" TB. It was the MDR-TB. The role of SRRT is to identify the people affected by the "potential" epidemic and its geographic extent, and to find ways to control it. In an attempt to do so, an "outbreak narrative" (Wald, 2008) was deployed as an heuristic 
tool. In the SRRT's report, Mo-e-se was indicated as the "source case" whose geographic whereabouts needed to be critically appraised.

The investigation by the SRRT was able to locate Mo-e-se's homestead. It was a small, Karen-styled thatched bamboo hut wherein ten of his relatives lived in close proximity. They were officially identified as "household contact" cases whose risk of contagion was very high. All of them were "screened" and, fortunately, all chest radiographs were normal. As six of them were children, they had to get the Tuberculin Skin Test to see if they had latent TB infection (LTBI), a non-symptomatic infection that can flare up later in their lives. The results were negative. Nevertheless, there was one of Mo-e-se's relatives missing, and nobody knew where she was. The only thing they knew was the chilling fact the woman now worked as a live-in nanny, caring for a child in Bangkok.

The story of Mo-e-se reveals the mobility of migrant workers and how their social networks across an expanded geographic area enabled them to travel near and far. His journey-from the border town of Umphang to a southern district in Songkhla, to the garment factory in Bangkok and finally to a sea-salt producing plant in Samut Sakorn-not only demonstrates to us the permeability of the border and the mobility of migrants across a long distance, transgressing all the formal logic of border and order. We can also see that distance and adjacency are relational. Economic necessity and sociality transform spatial remoteness into associational proximity. The biocontainment model of disease control which seeks to impose epidemiological territorial segregation upon peoples whose survival is everything but territorially bounded is deemed to fail. The logic of proximity, distance, and the border dynamics prompts us to reconsider the geometrics of how disease spreads, from the geometry of fixed distances and defined borders to "the potential for reassortments and rearrangements [that] make disease circumjacent" (Hinchliffe et al., 2013, p. 8). Geographic imagination in epidemiology needs to think of places not as an affixed location but with the well-defined border. Again, as Hinchliffe et al. put it, "[It] is a landscape in which borders are detached from the geographic territory, where the border can be embedded in pathogenic life itself, rather than at the edge of territories" (Hinchliffe et al., 2013, p. 8). With this new disease diagram, epidemic ceases to be a foreign threat. The reemergence of tuberculosis is a result of the rearrangement of spatial relations and the reassembling of the permeable borders, migration, economic opportunities, and the poor living conditions of migrants. This entangled mode of spatial relations, we believe, can lead us to rethink how disease epidemics and control can be conceived and practiced differently.

\section{Pathological life and biocontainment}

One of the fundamental premises underlying epidemiology is that diseases are not randomly distributed across time, places and persons; temporal variation, spatial differentiation, and population interact to create disease patterns. Epidemiology necessarily involves devising techniques to render complex spatiotemporal patterns of human activities legible. John Snow's well-known mapping of cholera incidence in London is an exemplar of employing a geographic device to understand an epidemic (Johnson, 2006). By taking the form of universal techniques of tracking incidences of diseases across spaces, epidemiology performs a key role in transforming a messy pathological world into a schema that can then be effectively intervened. As we can see from the case of Mo-e-se, however, the effect of technical intervention has never been easily predetermined. Rather than producing a unified result, application of global form always results in unintended consequences.
The rigid spatial notion of epidemiology forms the basis for the biocontainment model of disease control. In containing an epidemic outbreak, diseased bodies need to be identified and put under surveillance. Standardized classifications and categorizing schemes are developed and deployed for the purpose of singling out the contaminated from the healthy population (Hinchliffe et al., 2013). Measures are needed to make sure that the contaminated are not further spreading disease. In the 1990s, WHO (1994) institutionalized the idea that "treatment is the control."8 Treatment of every TB case is arguably the "only" means to stop the spreading and to control the global TB epidemic. Directly Observed Treatment, Short Course (DOTS) is a spearhead to make sure all patients diagnosed with TB are treated for a full course of medication regimen. DOTS is a program designed to eliminate patients' non-compliance behavior. Since the early days of the treatment program for TB was evaluated, it has been repeatedly found that a significant number of patients either dropped out from treatment or did not fully comply with continuing medication for the necessary period of at least six months. Failure to complete the course of treatment is considered one of the most critical factors contributing to the mycobacterium's mutation to drug-resistant strain. The treatment program of DOTS requires that there is an "observer," health personnel, a health volunteer, or, in specific circumstances, a family member, to witness the patient taking of medication.

The guidelines developed by WHO suggests that observers must ensure they witness the patient putting medication into his or her mouth and look into his or her mouth to make sure that the medicine was indeed swallowed. In Thailand, where a large number of DOT observers are the village health volunteers and community leaders, the script given to the observer was a simplified three-steps act: first, hand the medication to the patient (yib ya hai); second, watch as the patient swallow the medicine (du khao kluenkin), and, then, fill out the record form (set laew banthuek) (Department of Disease Control, n.d., p. back cover). The schematic, stepwise prescription of their role of the DOT observers unwittingly turns the patients into an object of bureaucratic surveillance and control. This standardized technique is an actualized form of assemblage which renders the complex world into a technological zone to which the seemingly neutral concepts can be applied. Technical rationality, abstract concepts, and expert knowledge system take on a universal character as they appear to be applicable anywhere the technique of the assemblage can be produced.

The DOT program exemplifies the concept of "treatment is the control." Infected cases need to be effectively treated to contain the spread of disease. Such a simplified concept, however, underestimates the complex human-tuberculosis relation and its pathogenesis. Studies in the natural history of tuberculosis show that less than one-third (30\%) of the people exposed to a "source case" become infected. After infection, only about three to ten percent of them develop the disease within the first year. Another three to five percent of them would develop it sometime later, while the rest will contain the latent infection throughout their life (Hopewell et al., 2016, p. 598, figure 35-3). Without any observable symptoms, these latent human carriers become a host in which $M$. tuberculosis silently inter-mingles with human bodies. Once reactivated, the bacillary load in a patient's sputum can be contagious.

Such a complex host-pathogenic agent relation, as recent advances in phylogenetic and bio-archeology of $M$. tuberculosis reveal, is a result of the tubercular co-evolution with hominids (Roberts and Buikstra, 2003). The mysterious dormant state of entanglement could be a signal of the microbial evolutional survival strategy, suggested Christopher Dye, an epidemiologist in the WHO Stop TB Department. "It's possible that latency evolved 
as a mechanism to avoid extinction when human populations were small and isolated," (Schmidt, 2008) As one of an up-to-date and comprehensive reference for biomedical knowledge puts it:

We are still far from understanding why the natural immune system (which prevents $90 \%$ of persons infected from developing active tuberculosis) fails in $10 \%$ of those infected and why the adaptive immune response in tuberculosis does not protect us from repeated infections (Hopewell et al., 2016, p. 628).

The ability of $M$. tuberculosis to lie dormant in human bodies for long periods of time without symptoms and to flare up later in an undetermined time reasserts the known fact that "Tubercle bacilli are a necessary, but not a sufficient, cause of TB." (Maher, 2009 , p. 129). In latent $\mathrm{TB}$, the pathogen has already resided within, awaiting a sufficient disease situation to trigger its pathogenesis. This indeterminacy of complex microbe-human entanglements produces a form of what Foucault calls pathological life. As Hinchliffe and colleagues (2013) put it:

Being healthy may not simply mean being free from pathogens, but a matter of immunocompetence... Life, in this view, becomes necessarily pathological, echoing Foucault's remark that ' $\mathrm{t}$ ] he idea of disease attacking life must be replaced by a denser notion of pathological life' (1973, p. 153). Disease, in this sense, becomes less about contamination and contagion, and more concerned with its systemic and endemic co-generation. (Hinchliffe et al., 2013, p. 537 , emphasis added)

Neither uncontaminated nor diseased, patients with latent TB are examples of pathological life par excellence. Such an ambiguous state poses a serious challenge to the biocontainment model of disease control which seeks to separate the contaminated from the healthy (Hinchliffe, 2001; Hinchliffe et al., 2017, p. 6). The fact is that almost a quarter of the entire human population are asymptomatic "carriers" (Houben and Dodd, 2016). This complex and indeterminacy of human-microbe entanglement extends beyond host-pathogen relationship to include exogenous factors, such as malnutrition, smoking, air pollution, alcohol, human immunodeficiency virus and the use of immunosuppressive drugs, which are known to play certain roles in the progression from latent to active $\mathrm{TB}$ disease. Socioeconomic status and behavioral factors are also shown to increase the susceptibility to infection. But the non-deterministic multifactorial nature of disease reactivation makes simple classification impossible.

\section{Fluid drug, DOTS and therapeutic assemblage}

No one knows what it's like when Mo-e-se took medication under the watchful eyes of the well-intentioned observer. He always seemed okay, or at least that was what health personnel who took care of him thought. He had been a "good patient." When he was first diagnosed and treated for his pulmonary tuberculosis back in Songkhla, he complied and adhered well to the treatment plan. He visited the doctor regularly and paid for the medication himself. His symptoms disappeared, and his CXR improved. He also willingly sought care when he developed symptoms again and returned to Umphang. His sputum smear microscopy was positive, and he was calm when diagnosed again with pulmonary TB. Even when the laboratory results showed his infection was MDR-TB and he needed to be isolated to prevent spreading the disease, he was accommodating. He was also "prescribed" DOTS. It is a well-known fact that the success rate of TB treatment has been low especially among migrants who, in the view of the TB program, often did not comply with the treatment plan. To solve this problem of "non-compliance," the healthcare team at Umphang came up with a solution.

Umphang Hospital is well known for its rigorous humanitarian efforts to provide medical care for all patients, regardless of their nationality or legal status. Knowing that it was extremely difficult for patients to travel to health facilities for the DOTS regimen, Dr. Worawit devised a plan of building houses to accommodate MDR-TB patients during the two-year period of necessary medication. Mo-e-se would be employed to work as a gardener, taking care of a plot of the herbal garden of the hospital. A small house was built for him to stay. Every day, a health officer who was responsible for "directly observing" his medication would come to visit him, calling him out to have his medication taken in front of her. Mo-e-se diligently complied. He knew how the hospital had been so kind not only providing the costly medication for his treatment but also building a house for him to stay close so he could receive medical supervision, all of which were provided free of charge. By putting him in close proximity, Dr. Worawit hoped it would ensure compliance and continuity of treatment.

Mo-e-se seemed grateful to be in the "TB village." But he also had other concerns. Since he left Myanmar as a young lad more than two decades ago, he had no official documents to prove his Burmese citizenship. Now that the political situation in Myanmar had improved, the possibility to return to his home opened up. Also, as Thailand had strengthened its immigration policy, it was crucial for him to get a Burmese passport to be legally registered as a migrant worker in Thailand. His relative who was still alive was his aunt. She was the only person that could verify Mo-e-se's citizenship status for an official document. Worried that his aunt was getting old and might pass away, he asked for permission from Umphang Hospital to return home for a few days to take care of this problem. The hospital agreed for him to leave, but he never returned. He had disappeared just a few months before the treatment regimen was to have been completed.

Mo-e-se was so close, yet unattainable, unable to being kept within bound. It was an unintended consequence, a result of the application of "techniques of rational calculation whose validity... rests on impersonal principles, which can be set out and developed without regard to context" (Collier, 2006, p. 400). His behavior could be easily dismissed as "erratic" or "irrational," but, as the long history of medical professionals attempting to promote rational drug use has repeatedly demonstrated, the question is whose rationality counts? Patients, especially those with chronic conditions requiring long-term medication in general, and tuberculosis patients in particular, are known to adjust doses, skip medication, take different combinations of drugs, or stop taking medication entirely. They asserted their own rationale in dispensing and administering their medication. The distinctive capacity of pharmaceuticals for decontextualize and recontextualize and the "fluidity" of the "articulations, dearticulations, and rearticulations of pharma-matter," resulting in unintended designs of drug use, has been well recognized (Hardon and Sanabria, 2017, pp. 118-119). Considering how a treatment regimen, together with the mutability of TB to MDR-TB and an ambiguous citizen status coincide in Mo-e-se's life situation, one can see the heterogeneous elements in the co-production of therapeutic assemblage. While the global forms of TB control strive to replace and reassemble how life is lived, Mo-e-se's ambiguous action can hardly be understood as a resistant political subject. The unintended consequence of "treatment-is-the-control" mentality points to the necessity of avoiding a simplistic biocontainment model of spatial segregation, and embracing the new possibilities of geometric ambiguity. 


\section{Conclusions}

Tuberculosis epidemics are both at the border and actively participating in co-creating borders. When the British imposed territoriality as the fundamental principle for a modern nation-state, border negotiations created particular spatial relations and sociomaterial conditions. The post-colonial bordering practices carry over to the spatio-political legacy that forces an arbitrary faultline and splits the Karen people at the border of two nations. In the ensuing decades, refugees fled war-torn homeland in Myanmar into Thailand, while migrants seeking economic opportunities traversed the borders and traveled across the country. Colonial days are long gone, yet the post-colonial legacy can still be felt in this borderland. It is not the visibility or physicality of the borderline that keeps people separate. Rather, it is the bordering practices that enact and maintain this spatial reality. The border, reified as it may be through forms of bordering practices, is not idly sitting at a geographical place somewhere between two nations. It has an active role in shaping local memories, histories, as well as how life is lived. People migrate across borders bringing with them materials, ideas, identities, as well as microbes.

The TB epidemic in this borderland seemingly resolves around mobility of migrants and microbes. But the borderland between Myanmar and Thailand has become a high-risk zone not simply because migrants were spreading disease as they roamed. Transborder tuberculosis emerged through the unfolding of the colonial past, border practices, socio-material conditions, and microbial natural history. The result is a space of assemblage in which mundane biotic and material encounters inevitably create the conditions of pathogenic communicability. As M. tuberculosis, and especially its drug-resistant strains, are perceived as traversing the borders, we argue that borders are multiple. Boundaries are practiced and constituted by various actors enacted through assorted elements, materials, and motives. The potency of $M$. tuberculosis to lie dormant in human bodies for long periods of time without symptoms poses an additional challenge to epidemiological attempts to segregate the healthy from the contaminated. Borders are indeterminate and the ways borders are made real-involve the multiplicity and indeterminacy of material, microbe, and human relations. As such, boundaries are always blurred and indeterminate. It was not merely geographic mobility of patients and the permeability of the border that undermined efforts to contain the spread of MDR-TB. Rather, it was the indeterminacy of borders, borders that were continuously co-produced and reproduced through complex microbe-human entanglements that challenged the adequacy of the spatially static biocontainment model.

In the globalizing world, in which rapid transportation and mobile technology facilitate long-distance sociality, faraway places can be "folded" into immediate proximity, allowing multiple and intensified forms of microbe-human interaction. Contingent borders and complex microbe-human entanglements necessitate changes in the prevailing biocontainment model of infectious disease control. We propose that disease surveillance and responses need to transcend the rigid geographic notion of space and include a more flexible topological conception of spatiality that embraces the fluidity of pharmaceuticals, microbes, and human relations. The reinvention of the spatial approach in epidemic control begins with close attention to the entanglement of human-microbe relations as biotic, abiotic, and antibiotic matters interact in the more-than-human borders.

\section{Data availability}

Data sharing is not applicable to this article as no datasets were generated or analyzed during the current study.
Received: 13 May 2018 Accepted: 13 February 2019

Published online: 12 March 2019

\section{Notes}

1 The Anti-tuberculosis Association of Thailand (established as The Anti-tuberculosis campaign of the Medical Association of Siam in 1934) became a member of International Union Against Tuberculosis and Lung Disease in 1957 (Songkram, 2003).

2 In 2017, the incident of TB in Myanmar and Thailand were 358 and 156 per 100,000 population, respectively (World Health Organization, 2018).

3 Our historical analysis of Siam-Burma border and the Karen in this paper is based primarily on the historical accounts of David Steinberg (2001), Jack Fong (2008), Charnvit (2011), and Dulyapak (2012).

4 By the availability of the "shorter" therapy for MDR-TB in Thailand, the duration of treatment for MDR-TB patients can be reduced from around two years to only nine months (Department of Disease Control, 2018).

$5 \mathrm{He}$ expressed this idea in a meeting at Umphang Hospital, December 2016.

6 Its official name is X-pert MTB/RIF. It used the technology of real-time polymerase chain reaction (PCR), to identify genetic material that is specific to Mycobacterium tuberculosis (MTB) and that specific to MTB that resists rifampicin (RIF).

7 Pseudonym.

8 WHO states that "strategies such as vaccinations, quarantines, ultraviolet lights, and expensive ventilation systems may be affordable for wealthy communities but are far less cost-effective in controlling the spread of the disease than simply treating contagious cases" (World Health Organization, 1994, p. 8).

\section{References}

Becker A, Motgi A, Weigel J, Giuseppe R, Basilico M, Hanna B, Kleinman A (2013) The unique challenges of metal health and MDR-TB: Critcal perspectives on metrics of disease. In: Farmer P, Kim JY, Kleinman A, Basilico M (eds) Reimagining global health: an introduction. University of California Press, Berkeley, p 212-244

Brown H, Kelly AH (2014) Material proximities and hotspots: Toward an anthropology of viral hemorrhagic fevers. Med Anthropol Q 28(2):280-303

Carrara VI, Sirilak S, Thonglairuam J, Rojanawatsirivet C, Proux S, Gilbos V, Krudsood S (2006) Deployment of early diagnosis and mefloquine-artesunate treatment of falciparum malaria in Thailand: the Tak malaria initiative. PLoS Med 3(6):e183

Charnvit K (2011) Collected treaties-conventions-agreements-memorandum of understanding and maps between Siam/Thailand-Cambodia-Laos-BurmaMalasia. The Foundation for The Promotion of Social Science and Humanities Textbooks Project, Bangkok

Collier SJ (2006) Global assemblages. Theory Cult Soc 23(2-3):399-401

Department of Disease Control (2016) Phon kandamnoen-ngan khuabkhum wannarok prathetthai pi ngobpraman 2552-2558 [Report of Tuberculosis Program Performance in Thailand, 2009-2015]. Department of Disease Control, Thai Ministry of Public Health

Department of Disease Control (2017) Panyutthasat wannarok radabchat por. sor. 2560-2564 [National Strategic Plan on Tuberculosis B.E. 2560-2564] Bangkok, Department of Disease Control, Ministry of Public Health

Department of Disease Control (2018) Naewtang kanraksa phupuai wannarok dueya lai khanan duai sutya rayasan 9 duean [Guideline Shorter Regimen for MDR-TB Treatment]. Bureau of Tuberculosis, Department of Disease Control, Bangkok

Department of Disease Control (n.d.) Samut bantuek sukhaphap [Health record notebook]. Department of Disease Control, Ministry of Public Health, Bangkok

Dulyapak P (2012) Phromdaen khong phama: prawattisat lae phumisat kanmueang [Boundaries of Burma: History and political geography]. In: Charnvit K (ed) Pramuan phaenthi: Prawattisat-phumisat-kanmueang kab latthiananikhom nai asian usakhane [Collected maps: History-geographypolitics and colonialism in Southeast Asia]. The Foundation for the Promotion of Social Science and Humanities Textbooks Project, Bangkok

Fong J (2008) Revolution as development: the Karen self-determination struggle against ethnocracy (1949-2004). Brown Walker Press, Boca Raton

Foucault M (1973) The birth of the clinic: an archaeology of medical perception. Pantheon Books, New York

Green S (2012) A sense of border. In: Wilson TM, Donnan H (eds) A companion to border studies. Blackwell Publishing, West Sussex, p 573-592

Gutierrez MC, Brisse S, Brosch R, Fabre M, Omaïs B, Marmiesse M, Vincent V (2005) Ancient origin and gene mosaicism of the progenitor of Mycobacterium tuberculosis. PLoS Pathog 1(1):e5

Hardon A, Sanabria E (2017) Fluid drugs: Revisiting the anthropology of pharmaceuticals. Annu Rev Anthropol 46(1):117-132. https://doi.org/10.1146/ annurev-anthro-102116-041539 
Hemhongsa P, Tasaneeyapan T, Swaddiwudhipong W, Danyuttapolchai J, Pisuttakoon K, Rienthong S, Varma JK (2008) TB, HIV-associated TB and multidrugresistant TB on Thailand's border with Myanmar, 2006-2007. Trop Med Int Health 13(10):1288-1296. https://doi.org/10.1111/j.1365-3156.2008.02139.x

Henry N (2011) People power: The everyday politics of democratic resistance in Burma and the Philippines. Doctoral Dissertation, Victoria University of Wellington

Hinchliffe S (2001) Indeterminacy in-decisions-science, policy and politics in the BSE (Bovine Spongiform Encephalopathy) crisis. Trans Inst Br Geogr 26 (2):182-204

Hinchliffe S, Allen J, Lavau S, Bingham N, Carter S (2013) Biosecurity and the topologies of infected life: from borderlines to borderlands. Trans Inst $\mathrm{Br}$ Geogr 38(4):531-543. https://doi.org/10.1111/j.1475-5661.2012.00538.x

Hinchliffe S, Bingham N, Allen J, Carter S (2017) Pathological lives: disease, space and biopolitics. John Wiley \& Sons, Chichester, West Sussex; Malden, MA

Hopewell PC, Kato-Maeda M, Ernst JD (2016) Tuberculosis. In: Broaddus VC, Mason RJ (eds) Murray and Nadel's textbook of respiratory medicine, 6th edn. Saunders, Elsevier Inc., Philadelphia, p 593-628.e520

Houben RM, Dodd PJ (2016) The global burden of latent tuberculosis infection: a re-estimation using mathematical modelling. PLoS Med 13(10):e1002152

Johnson S (2006) The ghost map: the story of London's most terrifying epidemicand how it changed science, cities, and the modern world. Penguin, New York

Keshavjee S, Farmer PE (2012) Tuberculosis, drug resistance, and the history of modern medicine. New Engl J Med 367(10):931-936. https://doi.org/10.1056/ NEJMra1205429

Kwanchewan B (2008) Moei river borderland and ethnic relation: Karen-Kon muang. Faculty of Social Sciences, Chiangmai University, Chiangmai

Latour B (1986) Visualization and cognition: thinking with eyes and hands. In: Latour B, Kuklick H, Long E (eds) Knowledge and society: studies in the sociology of culture past and present. pp. 1-40, MIT Press, Cambridge, Mass

Maher D (2009) The natural history of Mycobacterium tuberculosis infection in adults. In: Schaaf HS, Zumla AI (eds) Tuberculosis: a comprehensive clinical reference. Elsevier, Saunders, p 129-132

McMillen CW (2015) Discovering tuberculosis: a global history, 1900 to the present. Yale University Press, New Harven

Mol A (2002) The body multiple: ontology in medical practice. Duke University Press

Nadda S (2003) Lakkan lae phaen-ngan khuabkhum wannarok nai patchuban [Principles and the program of tubercolosis control in the present], 5th edn. In: Banyat P, Chaivej N, Songkram S (eds) Wannarok. Anti-tuberculosis Association of Thailand, Bangkok, $\mathrm{p}$ 64-93

Ranee W, Sompong S, Sasithorn T (2015) Pulmonary TB among Myanmar migrants in Samut Sakhon province, Thailand: A problem or not for the TB control program? Southeast Asian J Trop Med Public Health 46(2):296

Roberts CA, Buikstra JE (2003) The bioarchaeology of tuberculosis: a global perspective on a re-emerging disease. University Press of Florida, Gainesville, FL

Schmidt CW (2008) Linking TB and the environment: an overlooked mitigation strategy. Environmental Health Perspectives 116(11):A478-A485

Scott JC (1998) Seeing like a state: how certain schemes to improve the human condition have failed. Yale University Press, New Haven

Serres M, Latour B (1995) Conversations on science, culture, and time. University of Michigan Press, Ann Arbor

Songkram S (2003) Samakhom prab wannarok hang prathetthai nai phra borom rachupatham [The Anti-tuberculosis Association of Thailand under the royal patronage of His Majesty the King], 5th edn. In: Banyat P, Chaivej N, Songkram S (eds) Wannarok. Anti-tuberculosis Association of Thailand, Bangkok, p 26-30

Steinberg DI (2001) Burma: the state of Myanmar. Georgetown University Press, Washington, D.C.

Thongchai W (1994) Siam mapped: a history of the geo-body of a nation. University of Hawaii Press, Honolulu

Voravit S (2008) Displacement and disease: the Shan exodus and infectious disease implications for Thailand. Confl Health 2:4. https://doi.org/10.1186/17521505-2-4
Wald P (2008) Contagious: cultures, carriers, and the outbreak narrative. Duke University Press, Durham

World Health Organization (1994) TB: a global emergency. World Health Organization, Geneva

World Health Organization (2015a) End TB strategy. http://www.who.int/tb/ End_TB_brochure.pdf?ua $=1$

World Health Organization (2015b) Use of high burden country lists for TB by WHO in the Post-2015 era. https://www.tbfacts.org/wp-content/uploads/ 2016/06/high_tb_burdencountrylists2016-2020-1.pdf

World Health Organization (2018) Global tuberculosis report 2018. World Health Organization, Geneva

Yanai H, Uthaivoravit W, Panich V, Sawanpanyalert P, Chaimanee B, Akarasewi P, Mastro TD (1996) Rapid increase in HIV-related tuberculosis, Chiang Rai, Thailand, 1990-1994. AIDS 10(5):527-531

Yongyuth M, Somsri K, Suporn K, Kittipat I, Wittaya S (2014) Sathanakan wannarok due ya laikhanan changwat tak pi ngobpraman 2554-masayon 2557 [Situation of multidrug-resistant tuberculosis in Tak province, fiscal year 2011-2014]. Warasan wannarok roksruang-ok lae watbambat wikrit [Thai J Tuberc Chest Dis Crit Care] 35(1):8-17

\section{Acknowledgements}

We thank people in Umphang, Tak Province, who provided support to the research, especially Dr. Worawit Tantiwattanasap, Chantarapa Chindathong, Wanlee Khunyotying, and Rattikan Tassanipanit. We appreciate our Karen research assistances, Sittikon Taku and Warunee Sritrakunkiri, who not only helped in translation and collaboration, but also offered valuable insights from the young generation of Karen ethnic in Thailand. The research is funded by the Health System Research Institute, Thailand (grant \# HSRI 60-052). The preliminary phase of the study is supported by Harvard University Asia Center; Society and Health Institute, Ministry of Public Health, Thailand; and Umphang Hospital Foundation, Thailand. Additional support is provided by the Antimicrobials in Society (AMIS) project, London School of Hygiene and Tropical Medicine, UK. We further thank Coll Hutchison and Tony Bennett for help proofreading our manuscript and providing feedback. The research was reviewed and approved by the the Institutional Review Board of the Harvard University-Area (Protocol \# IRB 16-0694), and it received local ethical approval in Thailand from the Institute for the Development of Human Research Protections.

\section{Additional information}

Competing interests: The authors declare no competing interests.

Reprints and permission information is available online at http://www.nature.com/ reprints

Publisher's note: Springer Nature remains neutral with regard to jurisdictional claims in published maps and institutional affiliations.

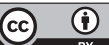

Open Access This article is licensed under a Creative Commons Attribution 4.0 International License, which permits use, sharing, adaptation, distribution and reproduction in any medium or format, as long as you give appropriate credit to the original author(s) and the source, provide a link to the Creative Commons license, and indicate if changes were made. The images or other third party material in this article are included in the article's Creative Commons license, unless indicated otherwise in a credit line to the material. If material is not included in the article's Creative Commons license and your intended use is not permitted by statutory regulation or exceeds the permitted use, you will need to obtain permission directly from the copyright holder. To view a copy of this license, visit http://creativecommons.org/ licenses/by/4.0/.

(c) The Author(s) 2019 